\title{
STUDI KOMPARATIF KEMAMPUAN ANAK MEMILIH JAJANAN SEHAT DI KOTA DAN DI DESA \\ (Studi di Kelurahan Sidorejo dan di Kelurahan Pangkut Pangkalan Bun)
}

\author{
Ibnu Habib Zein ${ }^{1}$ Rahaju Ningtyas ${ }^{2}$ Rukmini Syahleman ${ }^{3}$ \\ ${ }^{123}$ STIKes Borneo Cendekia Medika Pangkalan Bun
}

1. 1email : ibnuhabibzein@gmail.com, 2email : ningtyasrahaju@gmail.com,

3email : rukminisyahleman@gmail.com

\begin{abstract}
ABSTRAK
Generasi sehat harus mampu dalam memilih segala hal. Salah satunya adalah dalam memilih jajanan sehat. Memilih makanan sehat harus dibudayakan sejak usia dini. Pembelajaran dalam memilah dan memilih makanan sehat dimulai sejak dari rumah sehingga ketika berada di luar rumah anak-anak mampu memilih jajanan sehat untuk dikonsumsi. Perlu adanya pembelajaran dan pengertian dari orang-orang terdekat seperi orang tua, guru, dan keluarga. Tujuan penelitia ini adalah Studi komparatif kemampuan anak memilih jajanan sehat dikota di kelurahan Sidorejo dan didesa di Kelurahan Pangkut Pangkalan Bun. Desain penelitian yang digunakan dalam penelitian ini adalah deskriptif komparatif dengan pendekatan cross sectional. Populasi dalam penelitian ini adalah seluruh siswa SD yang berada di Kel. Sidorejo rt 03 dan di Kel. Pangkut rt 06 yang berjulah total 60 orang. Teknik sampling yang digunakan adalah simple random sampling. Variabel yang diguunakan adalah variabel penelitian, variabel penelitiannya adalah kemampuan anak memilih jajanan sehat. Kemampuan anak memilih jajanan sehat dikota masih belum mampu dan kemampuan anak memilih jajanan sehat didesa juga masih banyak yang belum mampu. Pengumpulan data menggunakan kuesioner dan di analisis menggunakan uji Mann-Whitney. Hasil uji statistik menggunakan uji Mann-Whitny di proleh nilai sig nya $(0,783)>(0,05)$ maka $\mathrm{H} 0$ di terima tidak ada perbedaan kemampuan anak memilih jajanan sehat dikota dan didesa. Kesimpulanya adalah tidak ada perbedaan dalam kemampuan anak memilih jajanan sehat di Kelurahan Sidorejo dan Kelurahan Pangkut.
\end{abstract}

Kata kunci : Anak Sekolah, Memilih Jajanan, Kota, Desa

\section{COMPARATIVE STUDY ABILITY OF CHILDREN CHOOSE HEALTHY JOURNEY IN THE CITY AND IN THE VILLAGE}

(Study in Sidorejo Urban Village and Pangkalan Bun Pangkalan Village)

\begin{abstract}
Healthy generation should be able to choose everything. One of them is in choosing healthy snacks. Choosing healthy foods should be cultivated from an early age. Learning in selecting and choosing healthy foods starts from home so that when outside the home the children are able to choose healthy. The need for learning and understanding from the closest people are like parents, teachers, and family. The
\end{abstract}


purpose of this research is a comparative study of the ability of children to choose healthy snacks in the city of Sidorejo and village in Pangkalan Bun Village. The research design used in this research is descriptive comparative with Cross sectional approach. The population in this study is all elementary students who are in Kel. Sidorejo rt 03 and in Ex. Pangk rt 06 which totals 60 people. Sampling technique in use is rendom sempling. Variables used are varabel research, research variables is the ability of children choose healthy snacks. The ability of children to choose healthy snacks in the city is still not able and the ability of children choose healthy snacks in the village are still many who have not been able. Data were collected using questionnaires and analyzed using Mann-Whitney test. The result of statistical test using Mann-Whitny test in proleh sig value $(0,783)>(0,05)$ then $\mathrm{HO}$ received no difference of ability of children choose healthy snack in town and village. Conclusion is no difference in the ability of children choose healthy snacks in the village Sidorejo and Pangkut Village.

Keywords: School Children, Healthy Snacks, Ability To Choose, City, Village

\section{PENDAHULUAN}

Generasi sehat harus mampu dalam memilih segala hal. Salah satunya adalah dalam memilih jajanan sehat. Memilih makanan sehat harus dibudayakan sejak usia dini. Pembelajaran dalam memilah dan memilih makanan sehat dimulai sejak dari rumah sehingga ketika berada di luar rumah anak-anak mampu memilih jajanan sehat untuk dikonsumsi. Anakanak memang sangat sulit terhindar dari beraneka macam jajanan yang ada di pasaran. Jajanan di pasaran beredar dengan beranekawarna, rasa dan bentuk. Tentunya sangat menarik bagi anak-anak. Walaupun orang tua sudah menyediakan camilan dan makanan di rumah, tetap saja tak jarang buah hati tetap saja jajan di luar. Padahal, selain boros, jajan di luar juga kita tidak bisa memastikan kebersihan serta nutrisinya. Belum lagi kita juga tidak mengetahui apakah makanan itu bebas dari zat kimia seperti boraks, formalin dan pewarna tekstil. Sebagaian besar anak tergoda dengan makanan yang berwarna warni atau bentuknya yang menarik. Meskipun ternyata tak sedikit dari makanan pilihan mereka itu terbukti tidak aman dikonsumsi. Untuk itu, mengajarkan kepada anak cara memilih jajanan yang sehat adalah hal yang sangat bijaksana untuk melatih kemandirian anak. Namun, memberi tahu anak tentang cara memilih jajanan yang sehat tidaklah mudah. Tetapi hal itu harus dilakukan demi kesehatan mereka. Sebab, anak merupakan generasi penerus bangsa. Kualitas bangsa di masa depan juga sangat tergantung dan ditentukan oleh kualitas anak-anak saat ini. Untuk itu upaya peningkatan sumber daya manusia harus dilakukan sejak usia dini, yakni pada masa tumbuh kembang anak. Perkembangan makanan jajanan di Indonesia yang berbasis home industry telah semakin maju, tak terkecuali yang dijajakan di sekolah-sekolah, hal ini dapat dilihat dengan semakin beragamnya makanan jajanan yang di tawarkan di setiap sekolah. Hampir disetiap sekolah, pasti dijumpai para pedagang makanan jajanan. Hal ini mendorong timbulnya kebiasaan mengkonsumsi makanan jajanan pada anak sekolah, terutama pada jam istirahat sekolah. Namun kebiasaan 
mengkonsumsi makanan jajanan sehat masih belum banyak dimiliki oleh anak sekolah.

Menurut data Food and Agriculture Organisation (FAO, 2013, 45), diperoleh data bahwa anak usia 6 sampai 11 tahun merupakan konsumen tersering dan terbesar dalam mengkonsumsi makanan jajanan. Kebiasaan mengkonsumsi makanan jajanan mengalami peningkatan yaitu 74\% menjadi 95\% dari tahun 2012 sampai 2013. Data di Indonesia merurut hasil survei Badan Pengawas Obat dan Makanan Repulik Indonesia (BPOM RI, 2013, 56), mendapatkan data bahwa $80 \%$ anak sekolah mengkonsumsi makanan jajanan di lingkungan sekolah baik dari penjaja maupun disekitar kantin sekolah. Frekuensi makanan ringan lebih dari 11 kali perminggu (66\%). Data penguji mutu kimia dan mikrobiologi yang dilakukan BPOM pada jenis makanan yang termasuk disk menu (olahan beras, olahan mie dan bihun, olahan daging, ungags, telur, ikan danolahan sayur). Menunjukan ada kandungan formalin (12.98\%), boraks $(9.74 \%)$, bakteri $\mathrm{S}$ aureus melibihi batas $(32.61 \%)$ dan 45.8 persen memiliki nilai total bakteri (ALT) melebihi batas. Sedangkan pada makanan ringan (aneka gorengan, chips, roti, wafer, permen, pentol, dan jajanan lainnya) di temukan 16,6 persen yang mengandung formalin, 22,78 persen memiliki nilai ALT melebihi batas, dan 15,56 persen sampel mengandung $\mathrm{S}$ aureus melebihi batas. Untuk minuman es di temukan 69,3 persen sampel yang mengandung E coli melebihi batas yang ditentukan. Berdasarkan hasil studi pendahuluanyang di lakuakan di kel. Sidorejo rt 03 dan kel. Pangkut rt 06. Di peroleh data jumlah siswa sekolah SD yang berada di kel. Sidorejo terdapat siswa sebanyak 30 orang siswa SD sedangkan di kel. Pangkut terdapat siswa sebanyak 30 orang siswa SD. Dari hasil pengumpulan data dengan cara wawancara yang di lakukan pada 10 orang siswa yang berada di kel. Sidorejo dari kelas (I - VI) dengan usia 6 - 12 tahun, di dapatkan data bahwa dari 10 anak yang di wawancara bahwa 7 (70\%) bahwa selalu membeli jajanan di sekolah seperti jajanan gorengan, pentol, batagor, es, dan jajanan kemasan. Dengan rincian 1 orang berasal dari kelas I, 2 orang kelas 3, 2 orang kelas 4,dan 2 orang kelas 5 . Sedangkan 3 orang sisanya $(30 \%)$ menyatakan bahwa dia jarang membeli jajanan walau pun pernah karna selalu membawa bekal dari rumah yang di siapkan oleh ibunya. Dan hasil pengumpulan data dengan cara wawancara yang di lakukan pada 10 orang siswa yang berada di kel. Pangkut rt 06 dari kelas (I - VI) dengan usia 6 - 12 tahun, di dapatkan data bahwa mereka semua selalu membeli makanan di kantin yang menjual makanan pokok dan jajanan kemasan seperti (nasi kuning, soto, dll). Karena penjual jajanan seperti batagor, gorengan, pentol, dan jajanan yang lain sangat jarang di SD mereka walau pun terkadang ada yang berjualan.

Kronologis terjadinya masalah adalah ketidakmampuan anak memilih jajanan. Rata-rata anak belum mengetahui pengetahuan tentang jajanan yang sehat atau pun jajanan yang berbahaya. Perlu adanya pembelajaran atau memberi pengetahuan pada anak-anak tentang jajanan. Makanan yang sehat, selain segar dan bersih juga tidak boleh mengandung bahan kimia yang berbahaya. Bahan-bahan kimia yang biasa ditambahkan kedalam makanan secara sengaja disebut bahan tambahan 
pangan (zat aditif pangan). Bahan kimia yang biasa ditambahkan ke dalam makanan saat pengolahan yaitu: Bahan pewarna, bahan pemanis, bahan pengawet, bahan pengenyal, bahan penambah rasa. Makanan sehat adalah dengan meramu berbagai jenis makanan yang seimbang, sehingga terpenuhi seluruh kebutuhan gizi bagi tubuh dan mampu dirasakan secara fisik dan mental (Prasetyono, 2009, 6). Bahan tambahan makanan umumnya berupa bahan-bahan kimia yang asing bagi tubuh. Oleh karena itu penggunaannya tidak boleh berlebihan, karena dapat berakibat kurang baik bagi kesehatan (Anonim, 2002, 9).

Dari data diatas peneliti ingin meneliti lebih lanjut tentang " studi komparatif kemampuan anak memilih jajanan sehat dikota dan didesa".

\section{METODE PENELITIAN}

Penelitian dengan bentuk deskriptif komparatif ini menggunakan pendekatan cross sectional. Populasi didalam penelitian ini adalah semua siswa SD yang berada di kel. sidorejo rt 03 dan kel. pangkut rt 06. Populasi seluruh siswa SD yang berada di kel. Sidorejo rt 03 berjumlah 30 siswa dan di kel. Pangkut berjumlah 30 siswa. Pengambilan sampel menggunakan simple random sampling dengan jumlah sampel didapat untuk masingmasing tempat sebanyak 28 siswa. Dalam pengambilan data digunakan kuesioner yang sebelumnya sudah di uji validitas dan reliabilitasnya. Penelitian ini dilaksanakan dari bulan februari hingga juni 2017. Analisa data yang digunakan adalah uji chi square.

\section{HASIL PENELITIAN}

\section{Data Umum}

Tabel 1 Distribusi frekuensi responden berdasarkan umur.

a. Kelurahan Sidorejo

\begin{tabular}{|c|c|c|c|}
\hline No. & Umur & Frekuensi & $\begin{array}{c}\text { Persentase } \\
(\%)\end{array}$ \\
\hline 1 & $\begin{array}{l}\leq 9 \\
\text { tahun }\end{array}$ & 11 & 36,7 \\
\hline 2 & $\begin{array}{l}10-11 \\
\text { tahun }\end{array}$ & 14 & 46,6 \\
\hline 3 & $\begin{array}{l}\geq 12 \\
\text { tahun }\end{array}$ & 5 & 16,7 \\
\hline & Jumlah & 30 & 100 \\
\hline
\end{tabular}

Berdasarkan tabel 1.1 menunjukkan bahwa sebagian besar dari responden di kelurahan Sidorejo Pangkalan Bun berumur $10-11$ tahun yaitu berjumlah 14 orang $(46,6 \%)$.

b. Kelurahan Pangkut Pangkalan Bun.

\begin{tabular}{cccc}
\hline No. & Umur & Frekuensi & $\begin{array}{c}\text { Persentase } \\
(\boldsymbol{\%})\end{array}$ \\
\hline 1 & $\begin{array}{c}\leq 9 \\
\text { tahun }\end{array}$ & 13 & 43,4 \\
2 & $\begin{array}{c}10-11 \\
\text { tahun } \\
\geq 12\end{array}$ & 10 & 33,2 \\
3 & $\begin{array}{c}\geq \text { tahun } \\
\text { Jumlah }\end{array}$ & 70 & 23,2 \\
\hline \multicolumn{3}{c}{ Sumber } & : Data umum 2017 \\
\hline
\end{tabular}

Berdasarkan tabel 1.2 menunjukkan bahwa sebagian besar dari responden di kelurahan Pangkut Pangkalan Bun berumur $\leq 9$ tahun yaitu berjumlah 13 orang $(43,4 \%)$.

Tabel 2 Distribusi frekuensi responden berdasarkan kelas. 
a. Kelurahan Sidorejo

\begin{tabular}{|c|c|c|c|}
\hline No. & Kelas & Frekuensi & $\begin{array}{c}\text { Presentase } \\
(\%)\end{array}$ \\
\hline 1 & $\begin{array}{c}\text { Kelas } \\
1-3\end{array}$ & 18 & 60 \\
\hline 2 & $\begin{array}{c}\text { Kelas } \\
4-6\end{array}$ & 12 & 40 \\
\hline & Jumlah & 30 & 100 \\
\hline
\end{tabular}

Berdasarkan tabel 2.1 menunjukkan sebagian besar responden di kelurahan Sidorejo Pangkalan Bun berasal dari kelas 1-3 yaitu sebanyak 18 orang $(60 \%)$.

b. Kelurahan Pangkut Pangkalan Bun.

\begin{tabular}{|c|c|c|c|}
\hline No. & Kelas & Frekuensi & $\begin{array}{c}\text { Presentase } \\
(\%)\end{array}$ \\
\hline 1 & $\begin{array}{c}\text { Kelas } \\
1-3\end{array}$ & 16 & 53.4 \\
\hline 2 & $\begin{array}{c}\text { Kelas } \\
4-6\end{array}$ & 14 & 46,6 \\
\hline & Jumlah & 30 & 100 \\
\hline
\end{tabular}

Berdasarkan tabel 2.2 menunjukkan sebagian besar responden di Pangkut Pangkalan Bun berasal dari kelas 1-3 yaitu sebanyak 16 orang $(53,4 \%)$.

Tabel 3 Distribusi frekuensi responden berdasarkan jenis kelamin

a. Kelurahan Sidorejo

\begin{tabular}{|c|c|c|c|}
\hline No. & $\begin{array}{c}\text { Jenis } \\
\text { kelamin }\end{array}$ & Frekuensi & $\begin{array}{c}\text { Presentase } \\
(\%)\end{array}$ \\
\hline 1 & Perempuan & 18 & 60 \\
\hline 2 & Laki-laki & 12 & 40 \\
\hline & Jumlah & 30 & 100 \\
\hline
\end{tabular}

Berdasarkan tabel 3.1 menunjukkan bahwa sebagian besar responden berjenis kelamin perempuan yaitu berjumlah 18 siswa (60\%).

b. Kelurahan Pangkut Pangkalan Bun.

\begin{tabular}{|c|c|c|c|}
\hline No. & $\begin{array}{c}\text { Jenis } \\
\text { kelamin }\end{array}$ & Frekuensi & $\begin{array}{c}\text { Presentase } \\
(\%)\end{array}$ \\
\hline 1 & Perempuan & 17 & 56,6 \\
\hline 2 & Laki-laki & 13 & 43,4 \\
\hline & Jumlah & 30 & 100 \\
\hline
\end{tabular}

Berdasarkan tabel 3.2 menunjukkan bahwa sebagian besar responden berjenis kelamin perempuan yaitu berjumlah 17 siswa $(56,6 \%)$.

Tabel 4 Distribusi frekuensi responden berdasarkan pernah atau tidak mendapat pengetahuan jajanan sehat

a. Kelurahan Sidorejo

\begin{tabular}{|c|c|c|c|}
\hline $\begin{array}{l}\text { N } \\
\text { o. }\end{array}$ & $\begin{array}{c}\text { Mendapat } \\
\text { pengetah } \\
\text { uan }\end{array}$ & $\begin{array}{c}\text { Frekue } \\
\text { nsi }\end{array}$ & $\begin{array}{c}\text { Persentase( } \\
\%)\end{array}$ \\
\hline 1 & Pernah & 22 & 73,4 \\
\hline \multirow[t]{2}{*}{2} & $\begin{array}{l}\text { Tidak } \\
\text { pernah }\end{array}$ & 8 & 26,6 \\
\hline & Jumlah & 30 & 100 \\
\hline
\end{tabular}

Berdasarkan tabel 4.1 menunjukkan bahwa sebagian responden di kelurahan Sidorejo Pangkalan Bun adalah pernah mendapat pengatahuan tenteng jajanan sehat sebanyak 22 orang $(73,4 \%)$.

b. Kelurahan Pangkut Pangkalan Bun.

\begin{tabular}{cccc}
\hline $\begin{array}{c}\text { N } \\
\text { o }\end{array}$ & $\begin{array}{c}\text { Mendapat } \\
\text { pengetahua } \\
\text { n }\end{array}$ & $\begin{array}{c}\text { Frekuen } \\
\text { si }\end{array}$ & $\begin{array}{c}\text { Persentas } \\
\text { e (\%) }\end{array}$ \\
\hline 1 & Pernah & 17 & 56,6 \\
2 & $\begin{array}{c}\text { Tidak } \\
\text { pernah }\end{array}$ & 13 & 43,4 \\
\hline & Jumlah & 30 & 100 \\
\hline \multicolumn{3}{l}{ Sumber : Data umum 2017 } &
\end{tabular}

Berdasarkan tabel 4.2 menunjukkan bahwa sebagian responden di kelurahan Pangkut Pangkalan Bun adalah pernah mendapat pengatahuan tenteng jajanan sehat sebanyak 17 orang $(56,6 \%)$. 
Tabel 5 Distribusi frekuensi responden berdasarkan sering tidaknya anak membeli jajanan sembarangan.

a. Kelurahan Sidorejo

\begin{tabular}{|c|c|c|c|}
\hline $\begin{array}{l}\mathbf{N} \\
\text { o. }\end{array}$ & $\begin{array}{l}\text { Jajanan } \\
\text { sembaran } \\
\text { gan }\end{array}$ & $\begin{array}{c}\text { Frekue } \\
\text { nsi }\end{array}$ & $\begin{array}{c}\text { Persentase } \\
\%)\end{array}$ \\
\hline 1 & $\mathrm{Ya}$ & 24 & 80 \\
\hline 2 & Tidak & 6 & 20 \\
\hline & Jumlah & 30 & 100 \\
\hline
\end{tabular}

Berdasarkan tabel 5.1 menunjukkan bahwa sebagian responden di kelurahan Sidorejo Pangkalan Bun sering membeli jajanan sembarangan sebanyak 24 orang $(80 \%)$.

b. Kelurahan Pangkut Pangkalan Bun.

\begin{tabular}{|c|c|c|c|}
\hline $\begin{array}{l}\mathbf{N} \\
\text { o. }\end{array}$ & $\begin{array}{l}\text { Jajanan } \\
\text { sembaran } \\
\text { gan }\end{array}$ & $\begin{array}{c}\text { Frekue } \\
\text { nsi }\end{array}$ & $\begin{array}{c}\text { Persentase } \\
\%)\end{array}$ \\
\hline 1 & Ya & 26 & 86,6 \\
\hline 2 & Tidak & 4 & 13,4 \\
\hline & Jumlah & 30 & 100 \\
\hline
\end{tabular}

Berdasarkan tabel 5.2 menunjukkan bahwa sebagian responden di kelurahan Pangkut Pangkalan Bun sering membeli jajanan sembarangan sebanyak 26 orang $(86,6 \%)$.

\section{Data Khusus}

Tabel 6 kemampuan anak memilih jajanan sehat.

\begin{tabular}{lcc}
\hline \multicolumn{3}{l}{ Kemampuan anak memilih jajanan sehat } \\
\hline Tempat & Mampu & Tidak mampu \\
\hline Kota & 6 & 24 \\
\hline Desa & 4 & 26 \\
\hline
\end{tabular}

Hasil uji statistik menggunakan uji Mann-Whitney di proleh nilai sig nya $(0,783)>((0,05)$ maka H0 di terima ada persamaan kemampuan anak memilih jajanan sehat dikota dan didesa.

\section{PEMBAHASAN}

\section{Mengidentifikasi kemampuan anak memilih jajanan sehat berdasarkan kebiasaan membeli jajanan sembarangan dikota.}

Berdasarkan tabel 5.1 menunjukan sebagian besar dari responden yang berada di kota masih banyak yang membeli jajanan sembarangan yaitu 24 orang (80\%).

Menurut peneliti berdasarkan data umum dikarnakan kurangnya keinginan anak untuk membeli jajanan sehat dikarnakan banyaknya penjaja jajanan sembarangan yang berada dilingkungan sekolah dan kurangnya pencegahan dari pihak sekolah untuk mengurangi penjaja atau penjual jajanan sehat di lingkungan sekolah. Dan juga kurangnya perhatian khusus dari pemerintah seempat seperti kelurahan dan puskesmas untuk mengevaluasi para penjaja atau penjualan agar bisa mengontrol dan memberi pengarahan pada para penjaja agar menjual jajanan yang aman dan sehat.

Irianto, P (2007, 8) pada umumnya anak-anak lebih menyukai jajanan diwarung maupun kantin sekolah daripada makanan yang telah tersedia dirumah.

\section{Mengidentifikasi kemampuan anak memilih jajanan sehat berdasarkan kebiasaan membeli jajanan sembarangan didesa.}

Berdasarkan tabel 5.2 menunjukkan bahwa sebagian responden di kelurahan Pangkut Pangkalan Bun sering 
membeli jajanan sembarangan sebanyak 26 orang $(86,6 \%)$. Sedangkan yang berada di desa sebanyak 17 orang $(56,6 \%)$ mendapatkan informasi. Banyaknya anak membeli jajanan sembarangan di pengaruhi beberapa faktor seperti pengatahuan dan informasi. Walaupun banyak siswa yang sudah mendapatkan pengetahuan dan informasi tetapi banyak yang belum sadar tentang bahaya makanan jajanan yang mereka beli atau konsumsi. Karna kurangnya kesadaran siswa dapat mempengaruhi kemampuan anak memilih jajanan sehat, sehingga begitu banyak anak masih membeli jajanan sehat walau pun masih ada perbedaan jumlah.

Menurut (Notoatmodjo, 2010, 76) pengetahuan yang dimiliki seseorang merupakan faktor yang sangat berperan dalam mengiterprestasikan stimulus yang kita peroleh.

\section{Studi komparatif kemampuan anak memilih jajanan sehat di kota dan desa.}

Berdasarkan tabel 6 dapat dilihat bahwa responden yang belum mampu memilih jajanan sehat di kota sebanyak 24 responden (80\%) dan di desa sebanyak 26 orang $(86,6$. Hasil uji Mann-Whitney diperoleh nilai sig nya $(0,783)>((0,05)$ maka $\mathrm{H} 0$ diterima ada persamaan kemampuan anak memilih jajanan sehat dikota dan didesadan $\mathrm{H} 1$ ditolak.

Umur atau usia juga berpengaruh terhadap kemampuan anak memilih jajajnan sehat. Berdasarkan tabel 5.1 didapatkan data sebagai berikut. Di kota sebanyak 14 orang $(46,6 \%)$ berumur $10-11$ orang, sedangkan di desa sebanyak 13 orang $(43,4)$ berumur $<9$ tahun. Pengambilan keputusan dapat di anggap sebagai suatu hasil atau keluaran dari proses mental atau kognitif yang membawa pada pemilihan suatu jalur tindakan di antara beberapa alternatef yang tersedia. Setiap pengambilan keputusan selalu menghasilkan satu pilihan final. Keluarnya bisa berupa suatu tindakan (aksi) atau suatu opini terhadap pilihan. Menurut George R. Terry pengambilan keputusan adalah pemilihan alternatif prilaku (kelakuan) tertentu dari dua atau lebih alternatif yang ada.

\section{KESIMPULAN DAN SARAN}

\section{Kesimpulan}

1. Kemampuan anak memilih jajanan sehat di kota hampir seluruhnya tidak mampu memilih jajanan sehat sebanyak 24 siswa (80\%).

2. Kemampuan anak memilih jajanan sehat di kota hampir seluruhnya tidak mampu memilih jajanan sehat sebanyak 26 siswa (84\%).

3. Tidak ada perbedaan kemampuan anak memilih jajanan sehat di kota dan di desa.

\section{Saran}

1. Bagi tenaga kesehatan (perawat komunitas)

Diharapkan bagi tenaga kesehatan dapat memberikan informasi berupa penyuluhan tentang bahaya jajanan sehat bahwa jajanan sembarangan dapat menimbulkan berbagai penyakit

2. Bagi peneliti selanjutnya

Diharapkan dapat melakukan penelitian tentang masalah dengan jajanan sehat. Hal ini dimaksudkan agar peneliti dapat menggali informasi secara mendalam tentang kemampuan anak memilih jajanan sehat. 
3. Bagi guru

Diharapkan bagi guru sebagai tenaga pengajar di sekolah jagat ikut aktif dalam meberikan pendidikan kesehatan tentang bahaya mengonsumsi jajanan sembarangan atau jajanan tidak sehat.

4. Bagi orang tua

Diharapkan bagi orang tua agar mampu membatasi atau mengontrol anak dalam memilih jajanan. Dan mampu mengarahkan anaknya agar mengonsumsi makanan yang sehat.

\section{DAFTAR PUSTAKA}

Anonim. 2002. Memilih Makanan dan Jajanan yang Sehat. Balitbang Depdiknas dan Lembaga Penelitian IPB. Bogor.

Irianto, K. 2007. Mikrobiologi Menguak Dunia Mikroorganisme. Bandung:Yrama Widya. h:75-94.

IFAD, WFP. "FAO (2013)." The State of Food Insecurity in the World: The multiple dimensions of food security (2013).

BPOM, RI. "Laporan Tahunan 2013 Badan Pengawas Obat dan Makanan RI."Jakarta: Badan POM RI (2013).

Prasetyono, Dwi Sunar. "Buku pintar ASI eksklusif." Cetakan pertama. Jogjakarta: Diva Press (Anggota IKAPI) (2009).

Notoatmodjo, Soekidjo. "Metodologi penelitian kesehatan." (2010).

Syamsi, Ibnu. 2000. Pengambilan Keputusan Dan Sistem Informasi. Jakarta: Bumi Aksara. 